\title{
Do analysts' earnings forecasts incorporate information in prior stock price changes?
}

\author{
Jeffery S. Abarbanell* \\ University of Michigan, Ann Arbor, MI 48109-1234, USA
}

Received September 1990, final version received April 1991

This research examines whether analysts' earnings forecasts incorporate information in price changes. Even if the forecasts do not explicitly depend upon price changes, there should nevertheless be a positive association between analysts' forecast revisions and prior price changes. Moreover, if analysts incorporate only their private information in formulating a forecast and ignore price changes, then the likelihood that their estimate is less than (greater than) the realization increases following price increases (decreases). Empirical results are consistent with these conjectures and indicate that analysts' forecasts do not fully reflect the information in prior price changes.

\section{Introduction}

The purpose of this paper is to study the formulation of financial analysts' earnings forecasts following security price changes. Identifying the influence of various signals on analysts' forecasts is important because of increasing use of these forecasts to represent market expectations of earnings. ${ }^{1}$

One empirical regularity that raises a question about how analysts' forecasts contribute to the formation of market expectations is the persistent

*I would like to thank Victor Bernard, Nicholas Gonedes, Richard Lambert, William Lanen, Craig Mackinlay, James Noel, Matthew Richardson, Douglas Skinner, Scott Stickel, Jerold Zimmerman (the editor), and Eric Noreen (the referee) for their helpful comments. Partial funding was provided by the University of Michigan School of Business Administration.

${ }^{1} A$ common empirical technique uses consensus forecast data to proxy for market expectations. This consensus has been formed using mean and median forecasts, e.g., Brown, Foster, and Noreen (1985). Fried and Givoly (1982) find analysts' forecasts to be superior to a variety of time series models of expectations with respect to their accuracy and strength of association with security returns. Brown, Griffin, Hagerman, and Zmijewski (1987) examines explanations for this observed superiority. 
finding that the sign and magnitude of analyst forecast revisions are positively associated with the sign and magnitude of prior security price changes, e.g., Givoly and Lakonishok (1979) and Brown, Foster, and Noreen (1985) (BFN). In this regard BFN comment:

'An important but unresolved issue is the extent to which analysts use prior security returns as a basis for revising their earnings forecasts. It would be difficult to explain, from an economic survival perspective, the continued employment of analysts to forecast earnings if all they are doing is re-expressing, in earnings forecast format, the information already available in publicly observable datum such as security price.' (p. 139)

The extent to which analysts' forecast revisions simply reflect the information in price changes that precede them bears directly on how they should be employed as a proxy for market expectations.

In the analysis below, it is assumed that analysts acquire private signals about earnings. If price changes are also informative about earnings, then changes in analysts' forecasts will be positively associated with prior price changes even if these forecasts do not explicitly incorporate the information conveyed in prior price changes. ${ }^{2}$ Moreover, if analysts' forecasts do not fully incorporate the information in prior price movements, then their forecast errors will be correlated with these price changes. This is true even if the independent signals acquired by analysts are more informative (precise) about earnings than price changes whose information content is excluded from analysts' forecasts.

Data from the Value Line Investment Survey are used to test whether information in prior price changes is fully reflected in analysts' earnings forecast revisions. The evidence indicates that the sign of analysts' forecast errors is not independent of the sign of prior price changes.

Section 2 outlines the basic market setting. Section 3 formulates hypotheses that relate forecast revisions and errors to prior security returns. Section 4 presents the empirical results. A summary and concluding remarks are found in section 5 .

\footnotetext{
${ }^{2}$ One explanation offered by BFN for the observed positive association between analysts' revisions and prior security returns is that there is a delay in the public dissemination of analysts' private information. The delay is of sufficient duration to make it appear as if analysts are mimicking price movements when, in fact, price is simply revealing the information analysts possessed prior to the price change. The case of a price change that only reflects analysts' previously private information is indistinguishable from the case of analysts issuing forecasts that simply re-express the information in a prior price change. This case raises an issue of timing as well as informativeness that is also relevant to evaluating the appropriateness of analysts' forecasts as earnings expectations.
} 


\section{The model}

BFN hypothesize that the positive association between analysts' forecast revisions and prior returns occurs because prices act as cues for analysts to acquire new information. The details of this explanation are not fully elaborated in their monograph. Abarbanell (1989) presents a model of a representative uninformed investor faced with a portfolio choice between a risky investment and a risk-free investment. In that model, a market maker sets price equal to the expectation of the risky asset conditional on orders received by informed and uninformed traders. In this setting, price communicates information in a noisy fashion [see also, e.g., Glosten and Milgrom (1985) and Diamond and Verrecchia (1987)]. That is, price can be informative about new earnings information without fully revealing the earnings even when they are known by some traders (insiders) with certainty. Price changes alter the uninformed trader's beliefs about the earnings of the risky investment and provide incentives to hire analysts to acquire new information before making an investment choice. ${ }^{3}$

\subsection{Price formation}

Consider a representative firm whose earnings can take on one of two values denoted $\omega_{h}$ and $\omega_{l}$ which represent a 'high' or 'low' state, respectively. ${ }^{4}$ If the high (low) state is revealed, the firm's value will be $r_{h}\left(r_{l}\right)$. The probability of the high (low) state occurring as assessed at time $t$, prior to the revelation of the earnings state is denoted prob $\left(\omega_{h}\right)\left(\operatorname{prob}\left(\omega_{l}\right)\right)$. The price of the firm at time $t$ is assumed to be:

$$
P^{\prime}=\operatorname{prob}\left(\omega_{h}\right) r_{h}+\operatorname{prob}\left(\omega_{l}\right) r_{l}
$$

The following conditions are assumed:

$$
\begin{aligned}
& \partial \operatorname{prob}\left(\omega_{h} \mid P^{t}\right) / \partial P^{t}>0, \\
& 0<\operatorname{prob}\left(\omega_{h} \mid P^{t}\right)<1, \quad \forall t .
\end{aligned}
$$

\footnotetext{
${ }^{3}$ Analysts in this model can be characterized as filters of noise in price. However, it is not necessary to assume that analysts are hired in response to price changes. The results presented later hold if analysts are hired prior to a price change but observe a price change before issuing a forecast. The relevant differences between these alternative constructions apply to the necessary conditions for hiring an analyst and the design of a compensation scheme to prevent the analyst from shirking and basing his forecast solely on the price change.

${ }^{4} \mathrm{An}$ alternative interpretation is that the two states represent an increase (decrease) in the expected (and currently priced) level of earnings.
} 
The first condition ensures that price increases (decreases) are accompanied by an increase in the probability of the high (low) earnings state as assessed by the market. The strict inequality in the second condition ensures that the market cannot perfectly infer the earnings state from observing price prior to the earnings announcement. The conditions are consistent with a noisy rational expectations equilibrium in which prices are informative about the earnings state but are not fully revealing [see, e.g., Diamond and Verrecchia (1987)].

\subsection{Analysts' signals}

Analysts employ an information system that will generate one of two possible signals, $y_{l}$ and $y_{h}$. The signal $y_{h}$ indicates that the state $\omega_{h}$ is more likely to occur and the signal $y_{l}$ indicates that the state $\omega_{l}$ is more likely to occur. ${ }^{5}$ The conditional probability of receiving the signal $y_{i}$ when the state is $\omega_{j}$ is $p_{i j}$ where $p_{l l}$ and $p_{h h}$ are strictly between 0.5 and 1 . It is assumed that the probabilities $p_{i j}$ that represent the analyst's information system are fixed and do not depend on price. The assumption implies that the signal produced by the analyst is not influenced by price changes.

\subsection{Properties of the analysts' reports}

In a rational market, participants would be expected to recognize that prices convey information and condition their decisions accordingly. Indeed, this supposition is the basis for the null hypotheses tested in this paper. However, to simplify the discussion the propositions that follow are based on analysts' forecasts that include only the analysts' private signals. The potential explanations for analysts' forecasts to exclude price changes are discussed in later sections. ${ }^{6}$

The first proposition demonstrates that even if information in prior price changes is omitted from analysts' forecasts, investors will anticipate a positive association between forecast revisions and prior price changes.

Proposition 1. The probability of receiving the report $y_{h}$ from a fixed information system is greater following a price increase than following a price decrease. The probability of receiving the report $y_{1}$ is greater following a price decrease than following a price increase.

\footnotetext{
${ }^{5}$ Under the alternative interpretation of the two earnings states $y_{h}$ and $y_{l}$ represent signals of an increase and decrease in expected earnings, respectively.

${ }^{6}$ The proofs of the propositions rely on the notion that while an individual analyst's forecast does not reflect price changes, the aggregate market (our representative investor) conditions on observed price changes when forming posteriors.
} 
Proof. The probability of a high earnings report is

$$
\operatorname{prob}\left(y_{h}\right)=\operatorname{prob}\left(\omega_{h} \mid P^{t}\right) p_{h h}+\left(1-\operatorname{prob}\left(\omega_{h} \mid P^{t}\right)\right) p_{h l} .
$$

The effect of a price change on this probability is

$$
\partial \operatorname{prob}\left(y_{h}\right) / \partial P^{t}=\left(p_{h h}-p_{h l}\right) \partial \operatorname{prob}\left(\omega_{h} \mid P^{t}\right) / \partial P^{t} .
$$

By assumption, $\partial \operatorname{prob}\left(\omega_{h} \mid P^{t}\right) / \partial P^{t}>0$ and $p_{h h}>p_{h l}$. Thus,

$$
\partial \operatorname{prob}\left(y_{h}\right) / \partial P^{t}>0 \text {. }
$$

Furthermore, because $\operatorname{prob}\left(y_{h}\right)+\operatorname{prob}\left(y_{l}\right)=1, \partial \operatorname{prob}\left(y_{l}\right) / \partial P^{t}<0$. Q.E.D.

Clearly, if analysts' forecasts incorporate information in prices, price changes and forecast revisions will be positively associated. However, even if the analyst ignores prior price changes when issuing a forecast, the high earnings report is more likely to follow a price increase and a low earnings report is more likely to follow a price decrease. The simple intuition behind this association is that when changes in price and the analyst's information system are both informative, the latter signal is more likely to 'confirm' rather than to contradict the former. ${ }^{7}$

However, the posterior probability of an accurate report by the analyst following a price change is only coincidentally the same for both earnings states when price change signals are omitted from forecasts. This point is summarized by Proposition 2. Define an inaccurate low earnings state report as $\left(\omega_{h} \mid y_{l}\right)$ and an inaccurate high earnings state reported as $\left(\omega_{l} \mid y_{h}\right)$.

Proposition 2. The probability of an inaccurate low earnings signal from a fixed information system (i.e., $p_{i j}$ do not depend on price) increases and the probability of an inaccurate high earnings signal decreases as price increases.

Proof. The probability of the high earnings state occurring following a low earnings signal is given by

$$
\begin{aligned}
& \operatorname{prob}\left(\omega_{h} \mid y_{l}\right) \\
& =\operatorname{prob}\left(\omega_{h}, y_{l}\right) / \operatorname{prob}\left(y_{l}\right) \\
& =\operatorname{prob}\left(\omega_{h} \mid P^{t}\right) p_{l h} /\left\{\operatorname{prob}\left(\omega_{h} \mid P^{t}\right) p_{l h}+\left(1-\operatorname{prob}\left(\omega_{h} \mid P^{t}\right)\right) p_{l l}\right\}
\end{aligned}
$$

\footnotetext{
${ }^{7}$ The analysis in Trueman (1988) leads to a similar prediction. Trueman explicitly models analysts' incentives to revise their earnings forecasts. In his setting analysts may issue biased forecasts and withhold information. In this paper analysts report their private information fully and truthfully.
} 
Similarly, the probability of the low earnings state occurring following a high earnings signal is given by

$$
\begin{aligned}
& \operatorname{prob}\left(\omega_{l} \mid y_{h}\right) \\
& =\operatorname{prob}\left(\omega_{l}, y_{h}\right) / \operatorname{prob}\left(y_{h}\right) \\
& =\left(1-\operatorname{prob}\left(\omega_{h} \mid P^{t}\right)\right) p_{h l} /\left\{\left(1-\operatorname{prob}\left(\omega_{h} \mid P^{t}\right)\right) p_{h l}+\operatorname{prob}\left(\omega_{h} \mid P^{t}\right) p_{h h}\right\}
\end{aligned}
$$

The changes in these respective probabilities with a change in price are given by

$$
\begin{aligned}
& \partial \operatorname{prob}\left(\omega_{h} \mid y_{l}\right) / \partial P^{t}=\left(\partial \operatorname{prob}\left(\omega_{h} \mid P^{t}\right) / \partial P^{t}\right) p_{l h} p_{l l} /\left(\operatorname{prob}\left(y_{l}\right)\right)^{2}, \\
& \partial \operatorname{prob}\left(\omega_{l} \mid y_{h}\right) / \partial P^{t}=-\left(\partial \operatorname{prob}\left(\omega_{h} \mid P^{t}\right) / \partial P^{t}\right) p_{h l} p_{h h} /\left(\operatorname{prob}\left(y_{h}\right)\right)^{2},
\end{aligned}
$$

By assumption, $\partial \operatorname{prob}\left(\omega_{h} \mid P^{t}\right) / \partial P^{t}>0$. Thus,

$$
\partial \operatorname{prob}\left(\omega_{h} \mid y_{l}\right) / \partial P^{t}>0 \text { and } \partial \operatorname{prob}\left(\omega_{l} \mid y_{h}\right) / \partial P^{t}<0 . \quad \text { Q.E.D. }
$$

As the probability of the high earnings state increases, price increases. If the analyst uses a fixed information system and ignores price, then his forecast will tend to be too low subsequent to a price increase and too high subsequent to a price decrease.

The intuition behind Proposition 2 carries over to the case in which analysts do not deliberately exclude the information in price changes in the formulation of their forecasts but sometimes fail to incorporate it. This phenomenon could, for example, be characterized by the exogenous imposition of the probability, $\alpha$, that analysts fail to observe a significant price change after it has taken place (where $0 \leq \alpha \leq 1$ ). A value of $\alpha$ greater than 0 could be attributable to limitations of time and resources faced by analysts. Only when $\alpha=0$ are price movements fully accounted for in analysts' forecasts.

The analysis of this section describes the implication for forecast errors when analysts' forecasts do not incorporate the information in prior price changes. The next section presents the results of empirical tests intended to determine if analysts' forecasts do, in fact, account for price changes in their forecasts. 


\section{Hypotheses}

To develop and test hypotheses based on the results of the last section, the high earnings signal is interpreted as a positive revision of a previously issued forecast and the low signal is interpreted as a negative revision of a previous forecast. ${ }^{8}$ Consistent with the empirical evidence cited earlier, Proposition 1 predicts a positive association between the signs of security price changes and subsequent analyst revisions.

Forecast errors are defined as estimated earnings per share minus actual earnings per share. If analysts' forecasts fully incorporate the information in price changes, then the sign of the forecast error resulting from a revision could not be predicted by prior price changes. On the other hand, Proposition 2 indicates that if the information in price changes is excluded from revisions, then underestimates (overestimates) become relatively more likely to follow positive (negative) price changes. ${ }^{9}$ That is, a negative association between the sign of the price change and the sign of the forecast error is predicted.

\subsection{Data selection}

The empirical tests of this section employ a sample obtained from The Value Line Investment Survey for firm fiscal years 1981-1984. The main advantage of this database is that it includes a single forecast for each firm whose effective date falls within a short interval prior to publication. ${ }^{10}$ Consensus data, such as $\mathrm{I} / \mathrm{B} / \mathrm{E} / \mathrm{S}$ summary estimates include forecasts that may have been formulated as many as two months prior to the $I / B / E / S$ publication date. Reliance on Value Line forecasts and publication dates increases the likelihood that price changes that were actually observable to analysts prior to a forecast revision are properly delineated. The vast majority of Value Line forecasts pertain to primary earnings per share before extraordinary items and discontinued operations. Exceptions are explicitly stated in notes to the forecast. Four years of quarterly earnings forecasts were collected for one hundred firms randomly selected from a set of firms that met

\footnotetext{
${ }^{8}$ Clearly a given analyst's previous forecast of earnings may on occasion be greater (less) than the level implied by current price that aggregates all participants' information. In these cases a high (low) signal may already be reflected in an analyst's outstanding forecast and no revision will be observed. If high and low signals are given equal emphasis in analysts' forecasts when they are acquired, then these cases will weaken the predicted associations to be tested but should not bias the empirical tests.

${ }^{9}$ In the empirical tests that follow an overestimate (underestimate) occurs when the last outstanding forecast prior to earnings announcement overshoots (undershoots) the actual earnings number.

${ }^{10}$ The identification of the effective date of a forecast is discussed further in section 3.4.
} 
Table 1

Sample description.

\begin{tabular}{lccc}
\hline \multicolumn{4}{c}{ Panel A: 1984 sample market value of common equity (\$ millions) } \\
& Sample firms & $\begin{array}{c}\text { Firms common } \\
\text { to Value Line } \\
\text { and Compustat }\end{array}$ & $\begin{array}{c}\text { Firms on } \\
\text { Compustat }\end{array}$ \\
\hline Mean & $\$ 1,555$ & $\$ 1,371$ & $\$ 884$ \\
Median & $\$ 379$ & $\$ 378$ & $\$ 116$ \\
$N$ & 100 & 1022 & 2318 \\
\hline
\end{tabular}

Panel B: Number of earnings forecasts and revisions by year

\begin{tabular}{lrrrrr} 
& 1981 & 1982 & 1983 & 1984 & $\begin{array}{r}\text { All } \\
\text { years }\end{array}$ \\
\hline Number of firms & 100 & 100 & 100 & 100 & 100 \\
Usable forecasts & 336 & 377 & 306 & 351 & 1370 \\
Lost to stock splits & 64 & 23 & 94 & 49 & 230 \\
Total forecasts & 400 & 400 & 400 & 400 & 1600 \\
\hline
\end{tabular}

Panel C: Revisions by sign and as a percentage of prior forecast

\begin{tabular}{|c|c|c|c|c|c|c|}
\hline Size of revision & Sign of revision & 1981 & 1982 & 1983 & 1984 & $\begin{array}{c}\text { All } \\
\text { years }\end{array}$ \\
\hline $\begin{array}{l}\text { Absolute size of } \\
\text { revision greater } \\
\text { than } 10 \%\end{array}$ & $\begin{array}{l}\text { Positive } \\
\text { Negative }\end{array}$ & $\begin{array}{r}58 \\
102\end{array}$ & $\begin{array}{r}30 \\
167\end{array}$ & $\begin{array}{r}50 \\
109\end{array}$ & $\begin{array}{r}40 \\
102\end{array}$ & $\begin{array}{l}178 \\
480\end{array}$ \\
\hline $\begin{array}{l}\text { Absolute size of } \\
\text { revision between } \\
5 \% \text { and } 10 \%\end{array}$ & $\begin{array}{l}\text { Positive } \\
\text { Negative }\end{array}$ & $\begin{array}{l}22 \\
33\end{array}$ & $\begin{array}{l}15 \\
32\end{array}$ & $\begin{array}{l}20 \\
23\end{array}$ & $\begin{array}{l}27 \\
42\end{array}$ & $\begin{array}{r}84 \\
130\end{array}$ \\
\hline \multirow[t]{2}{*}{ All revisions } & $\begin{array}{l}\text { Positive } \\
\text { (\% of revised) }\end{array}$ & $\begin{array}{r}104 \\
(40 \%)\end{array}$ & $\begin{array}{r}68 \\
(23 \%)\end{array}$ & $\begin{array}{r}84 \\
(36 \%)\end{array}$ & $\begin{array}{r}98 \\
(36 \%)\end{array}$ & $\begin{array}{r}354 \\
(33 \%)\end{array}$ \\
\hline & $\begin{array}{l}\text { Negative } \\
\text { (\% of revised) }\end{array}$ & $\begin{array}{r}159 \\
(60 \%)\end{array}$ & $\begin{array}{r}231 \\
(77 \%)\end{array}$ & $\begin{array}{r}151 \\
(64 \%)\end{array}$ & $\begin{array}{r}172 \\
(64 \%)\end{array}$ & $\begin{array}{r}713 \\
(67 \%)\end{array}$ \\
\hline No change & & 73 & 78 & 71 & 81 & 303 \\
\hline Total & & 336 & 377 & 306 & 351 & 1370 \\
\hline
\end{tabular}

all of the following criteria:

1. Inclusion in the (1987) NYSE-AMEX CRSP Daily Returns file for the period between 1980 and 1985.

2. Earnings data available on the Quarterly Compustat Industrial tape for the period between 1980 and 1985 .

3. Quarterly forecasts included in The Value Line Investment Surcey for the period between 1980 and 1985.

Panel A of table 1 presents mean and median market value of equity for three separate groups of firms. The first column of panel A describes firms in 
the selected sample. The second and third columns present similar descriptive statistics for all firms common to Value Line and Compustat during 1984 and all firms listed on the Quarterly Compustat Industrial tape during 1984, respectively. A comparison reveals that the sample selected from the firms listed on both Compustat and Value Line are biased toward the larger companies.

Panel B of table 1 presents information about the number of quarterly earnings forecasts for the sample firms in the fiscal years ending in 1981 through 1984. When stock splits occur, it is often difficult to ensure that analysts' EPS forecasts are based on the same number of shares used in the calculation of announced EPS. Therefore, forecasts pertaining to firm years in which splits occurred are excluded from the sample. To avoid potential problems introduced by serial correlation in forecast revisions only the last earnings forecast before an actual quarterly earnings announcement is used in the empirical tests. ${ }^{11}$

\subsection{Revision tendencies and frequency}

One interesting aspect of the data presented is found in panel $\mathrm{C}$ of table 1. The number of downward revisions is substantially greater than the number of upward revisions in every year. This is true regardless of the relative magnitude of the revision. This finding is consistent with Jain (1988) who found that negative revisions represent almost three quarters of all revisions in the $1 / B / E / S$ database for the years 1976 to $1986 .{ }^{12}$ Stickel (forthcoming) finds that the intercept term of a prediction model of revisions is significantly negative for Zacks data over the period 1980-1985, indicating an average downward revision. The revision characteristics of Value Line data appear to resemble other analyst forecast sources for the sample period.

\subsection{Forecast errors: Bias and accuracy}

Data describing the characteristics of forecast errors are presented in panel A of table 2. Forecast errors are calculated as follows:

$\left(\right.$ Forecasted EPS ${ }_{i t}-$ Actual EPS $\left._{i}\right)$,

\footnotetext{
${ }^{11}$ This correlation may be the result of a trend in an economic variable that impacts on firm earnings. Several revisions may occur before the full magnitude of the trend is fully apparent to forecasters and included in their forecasts.

${ }^{12} \mathrm{BFN}$ find no significant difference in the sign of individual and consensus revisions for the 500 firms represented in their I/B/E/S sample from 1976-1980. If their sample was representative of the 1976-1980 period, then it may be inferred that the tendency for negative revisions found by Jain and Stickel is attributable to the post-1980 years. These years subsume the sample period in this study.
} 
Table 2

Description of forecast errors.

Panel A: Summary statistics for mean error $(M E)$, mean absolute error $(M A E)$, and mean squared error (MSE); $N=1370$

\begin{tabular}{lccc} 
& $M E$ & MLE & MSE \\
\hline Mean & 0.04 & 0.18 & 0.15 \\
Median & 0.01 & 0.10 & 0.01 \\
Std. dev. & 0.38 & 0.34 & 1.15 \\
IQR $^{\mathrm{a}}$ & 0.18 & 0.15 & 0.03 \\
\hline
\end{tabular}

Panel B: Distribution of forecast errors by tiscal year ${ }^{b}$

\begin{tabular}{|c|c|c|c|c|c|c|c|c|}
\hline & \multicolumn{4}{|c|}{ Overestimates } & \multicolumn{4}{|c|}{ Underestimates } \\
\hline & $\bar{N}$ & Mean & Median & Std. dev. & $\bar{N}$ & Mean & Median & Std. dev. \\
\hline 1981 & 177 & 0.21 & 0.10 & 0.35 & 152 & -0.23 & -0.12 & 0.44 \\
\hline 1982 & 212 & 0.24 & 0.12 & 0.41 & 152 & -0.13 & -0.09 & 0.18 \\
\hline 1983 & 160 & 0.17 & 0.11 & 0.24 & 134 & -0.20 & -0.10 & 0.49 \\
\hline 1984 & 178 & 0.20 & 0.08 & 0.32 & 152 & -0.11 & -0.07 & 0.13 \\
\hline Total & 727 & 0.21 & 0.10 & 0.34 & 590 & -0.17 & -0.09 & 0.34 \\
\hline
\end{tabular}

Interquartile range.

${ }^{b}$ Excluding observations for which reported EPS equals forecasted EPS.

where the subscript $i$ denotes firm and $t$ the forecast date. Deflating forecast errors by stock price just prior to the date of the forecast to control for cross-sectional differences in earnings levels does not qualitatively alter the descriptive measure patterns seen in table 2 or the statistical tests described later in footnotes 22 and 24 . Deflating by stock price is not relevant for the test presented in section 4 .

The mean forecast error is positive (overestimate) in every year, consistent with prior research, e.g., Fried and Givoly (1982), BFN (1985), and O'Brien (1988)..$^{13}$ Panel A of table 2 includes a summary of two common measures of forecast accuracy: the mean absolute error and the mean square error (MSE). Abarbanell (1989) reports a consistent decline in the magnitude of both measures in each quarter's outstanding forecast as the EPS announcement date is approached. Overall, the Value Line forecast accuracy characteristics are consistent with those reported in the literature for other databases such as $I / B / E / S$ [e.g., BFN (1985)], Zacks [e.g., Stickel (1988)], and The Earnings Forecaster [e.g., Fried and Givoly (1982)].

Panel B of table 2 presents evidence on the incidence of forecast overestimates and underestimates for quarterly earnings forecasts by fiscal year. Fifty-three observations for which reported earnings equalled forecasted

\footnotetext{
${ }^{13}$ O'Brien reports that the median forecast error for $\mathrm{I} / \mathrm{B} / \mathrm{E} / \mathrm{S}$ detail data over the period 1975-1981 was an overestimate but not generally significantly different from zero.
} 
earnings are excluded. Forecast error data are based on firm earnings announcements as reported by Value Line. Forecast errors based on earnings as reported by Compustat were also examined. ${ }^{14}$ Choice of actual earnings source did not significantly affect the distribution of forecast errors described in this section. Results are reported for Value Line actual earnings announcements only.

The rate of overestimation exceeds the rate of underestimation in each of the four fiscal years which is consistent with Fried and Givoly (1982). BFN (1985), however, find for their sample of I/B/E/S consensus forecasts that underestimates were more likely to occur than overestimates. ${ }^{15}$ The excess of overestimates over underestimates was a consideration contributing to the choice of tests discussed in the next section.

\subsection{Returns}

Two variables representing price changes are calculated. The first is a raw returns variable, denoted $R E T$, which is the average daily return for a firm between earnings forecasts. The period is referred to as the cumulation interval. The second price change variable is based on abnormal returns and is calculated by cumulating daily abnormal returns during the cumulation interval and dividing by the number of days between forecasts. ${ }^{16}$ This variable is denoted $C A R$.

The raw return variable is included because abnormal returns are, by construction, orthogonal to market returns. A potential problem arises in a

\footnotetext{
${ }^{14}$ The two services agree on over $75 \%$ of the usable reported earnings. Of the announcements for which there is a discrepancy, a large majority differ by trivial amounts. Adjustments were made, where possible, to reconcile the two numbers of primary EPS. Philbrick and Ricks (1989) report that pairing Value Line EPS forecasts with Value Line earnings and announcements leads to less absolute forecast error than pairing Value Line forecasts with Compustat actual earnings. They also report stronger associations in tests that associate excess returns and Value Line actual earnings announcements as compared with tests using Compustat announcements.

${ }^{15}$ It is possible that analysts tend to be optimistic in their estimates because they wish to maintain good relations with management. Abarbanell (1989) reports that the average overestimate declines steadily over the six months prior to an announcement. The average underestimate over time remains relatively stable, however. Analysts gradually purging forecasts of elements that are inflated relative to new information is consistent with these two patterns. An alternative explanation for the observed tendency to overestimate is offered by O'Brien (1988). She argues that it results from unanticipated macroeconomic (bad news) events that are recognized only subsequent to analysts' forecasts for a particular period. If this explanation is correct there would be no a priori reason to expect one type of forecast error to be more likely than another. The relative impact of these competing hypotheses is currently an unresolved issue.

${ }^{16}$ For each revision observation a cumulative abnormal return is calculated using the following market model specification: $\sum_{t}\left(R_{i t}-\alpha_{i}-\beta_{i}\left(R_{m t}\right)\right)$ where $R_{i r}$ is the return for firm $i$ on day $t$. $R_{m}$ is the equally weighted market return on day $t$. The parameters $\alpha_{i}$ and $\beta_{i}$ were estimated using daily returns between week +26 and +52 relative to the last earnings forecast [see Copeland and Mayers (1982)].
} 
forecasting context because market returns reflect information about how market-wide events will affect firm earnings. These market-wide events are likely to be factored into analysts' forecasts. ${ }^{17}$ Results in the next section are reported for both raw and abnormal returns.

A final issue related to calculating returns is the delay between the date Value Line analysts formulate an earnings estimate (which is unobservable) and the date this estimate is published. The publication date on Value Line is defined as the 'public forecast date'. Forecasts to be printed on a particular Friday are typically collected from analysts by the Monday of that week. Subsequently analysts may, on occasion, submit a supplemental report with a revision up to the date of publication if a significant event transpires. To ensure that only security returns potentially observable to the analyst prior to a forecast are included in the price change variable, returns for a given firm are cumulated up to ten days prior to the public forecast date. That is, the cumulation interval runs from the previous public forecast date to ten days prior to the public forccast date. The ten-day cutoff is likely to exclude returns occurring after Value Line submits its forecast to the printer but before the public forecast date. ${ }^{18}$

Two additional specifications for cumulating returns were also considered. The first employs a cumulation interval that runs from ten days prior to the previous public forecast date to ten days prior to the public forecast date. The second cumulates returns between consecutive public forecast dates. The overall results of the empirical tests reported in the next section are not sensitive to these specifications Results for individual years are generally unchanged under alternative cumulation intervals. Individual year differences are noted where appropriate.

\section{Empirical results}

\subsection{Tests of association between prior returns and revisions}

The first test of this section is intended to establish that the positive association between analysts' forecast revisions and prior security returns which is predicted by Proposition 1 and observed in other databases is found in the Value Line sample.

Proposition 1 predicts that

$$
\operatorname{prob}\left[y_{h} \mid P^{1}>P^{0}\right]>\operatorname{prob}\left[y_{h} \mid P^{1}<P^{0}\right]
$$

\footnotetext{
${ }^{17}$ The difficulties engendered by first calculating abnormal returns and then associating them with other variables is discussed in Beaver (1987). Abarbanell (1989) suggests additional statistical reasons for favoring the use of raw returns rather than abnormal returns in these tests and presents evidence that indicates there is a significant component to analyst forecasts revisions which represents the effect of market movements on individual firms.

${ }^{18}$ Cumulating returns up to five days prior to the last forecast did not cause substantiative differences in the results described below.
} 
and

$$
\operatorname{prob}\left[y_{l} \mid P^{1}<P^{0}\right]>\operatorname{prob}\left[y_{l} \mid P^{1}>P^{0}\right] \text {. }
$$

The test of this proposition employs the following statistic:

$$
\text { freq }[\operatorname{Rev}>0 \mid \operatorname{Return}>0]-\text { freq }[\operatorname{Rec}>0 \mid \text { Return }<0]>0 \text {, }
$$

where $R e v>0(<0)$ denotes an upward (downward) revision and Return is measured by the RET and CAR variables described in the last section. ${ }^{19}$

If, $e x$ ante, positive and negative price changes occur with equal frequency and positive and negative revisions also occur with equal frequency, then under a null hypothesis of independence between the sign of revisions and prior price changes this test statistic is equivalent to a phi coefficient calculated for a $2 \times 2$ contingency table categorized by the signs of returns and revisions. ${ }^{20} \mathrm{~A}$ normal approximation can be used to assess significance in this case [see Conover (1971)]. While the frequencies of positive and negative return observations are expected to be close to equal when abnormal returns measure price changes, the same is not true when raw returns are used. Further, the empirical evidence found in the literature is inconclusive with regard to the ex ante probability of observing positive and negative revisions. The prolonged excess of negative revisions over positive revisions observed in the sample, however, suggests the possibility of a systematic difference in their likelihoods. Because the distribution of the test statistic in (3) is unknown in this circumstance, an approximate randomization test is used to assess significance. ${ }^{21}$ Under the null hypothesis that earnings revisions are unrelated to price changes, the test proceeds by shuffling the revisions relative to price changes. The significance level of the test is based on the number of times the value of the test statistic in the shuffled data exceeds the value in the original sample. [See Noreen (1989) for details.]

Table 3 presents results along with contingency tables categorized by the sign of the revision and the sign of prior raw returns ( $R E T$ ) and prior abnormal returns $(C A R)$. The hypotheses tested in this section are conditional on the analyst revising a previously outstanding forecast, therefore, zero revision observations are excluded. Results for individual fiscal years and all years aggregated are reported.

Based on the randomization test the null hypothesis of independence between the signs of revisions and $R E T$ is rejected in favor of the alternative

\footnotetext{
${ }^{19}$ Because the earnings state is limited to two outcomes a test of prob $\left[y_{h} \mid P^{\mathrm{l}}>P^{0}\right]>$ $\operatorname{prob}\left[y_{h} \mid P^{1}<P^{0}\right]$ is, simultaneously, a test of prob $\left[y_{l} \mid P^{1}<P^{0}\right]>\operatorname{prob}\left[y_{l} \mid P^{1}>P^{0}\right]$.

${ }^{20}$ The phi coefficient, $\phi$, is equal to $\left(\left(N_{p p} N_{n n}-N_{n p} N_{p n}\right) /\left(N_{p} . N_{. p} N_{n} \cdot N_{. n}\right)\right)^{1 / 2}$, where $N_{. p}$ and $N_{\cdot n}$ denote column totals and $N_{p}$. and $N_{n}$. denote row totals for the $2 \times 2$ tables in table 3 . $\phi$ differs from the statistic in (3) by a factor of $\left(N_{\cdot p} N_{\cdot n} / N_{p} . N_{n} .\right)^{1 / 2}$.

${ }^{21}$ The values of the proposed test statistic and phi coefficients for each year and in aggregate are very similar. The $p$-values obtained through the randomization tests are very close to those which result from tests using a normal approximation.
} 
Table 3

Approximate randomization tests.

Statistic: freq[ $\operatorname{Ret}>0 \mid$ Returns $>0]-$ freq[ $\operatorname{Ret}>0 \mid$ Returns $<0]$

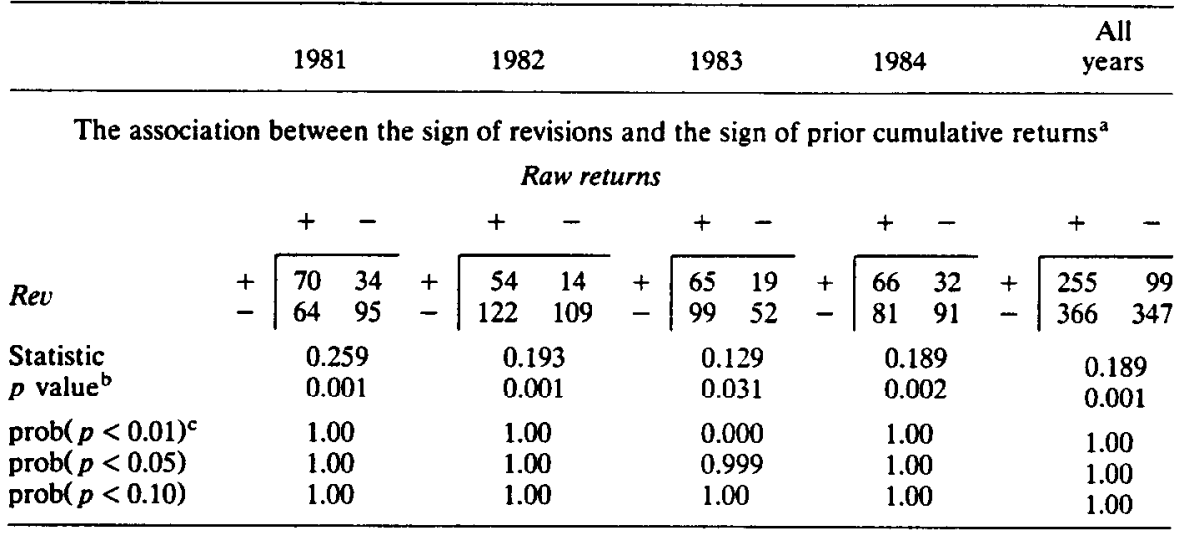

The association between the sign of revisions and the sign of prior cumulative abnormal returns ${ }^{\mathrm{a}}$

\begin{tabular}{|c|c|c|c|c|c|c|c|c|c|c|c|c|c|c|c|}
\hline & & & & & & $C$ & & & & & & & & & \\
\hline & & + & - & & + & - & & + & - & & + & - & & + & - \\
\hline $\operatorname{Rev}$ & + & $\begin{array}{l}64 \\
64\end{array}$ & $\begin{array}{l}40 \\
95\end{array}$ & + & $\begin{array}{r}49 \\
108\end{array}$ & $\begin{array}{r}19 \\
123\end{array}$ & + & $\begin{array}{l}32 \\
52\end{array}$ & $\begin{array}{l}52 \\
99\end{array}$ & $\stackrel{t}{-}$ & $\begin{array}{l}68 \\
82\end{array}$ & $\begin{array}{l}30 \\
90\end{array}$ & + & $\begin{array}{l}213 \\
306\end{array}$ & $\begin{array}{l}141 \\
407\end{array}$ \\
\hline $\begin{array}{l}\text { Statistic } \\
p \text { value }\end{array}$ & & & & & & & & & & & 0.2 & & & & \\
\hline $\begin{array}{l}\operatorname{prob}(p<0.01) \\
\operatorname{prob}(p<0.05) \\
\operatorname{prob}(p<0.10)\end{array}$ & & $\begin{array}{l}1 . \\
1 . \\
1 .\end{array}$ & & & & & & & & & $\begin{array}{l}1.0 \\
1.0 \\
1.0\end{array}$ & & & & \\
\hline
\end{tabular}

\footnotetext{
${ }^{a}$ Returns are cumulated between the previous public forecast date up to ten days before the public forecast date.

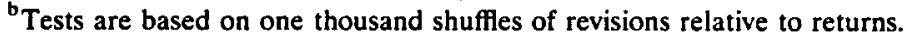

${ }^{c}$ Represents the posterior probability that the approximated significance level of the test is less than or equal to a given rejection level for the test. The significance level is a function of the number of shuffles and the number of times the test statistic for the shuffled data equals or exceeds the value computed for the original data. A uniform $[0,1]$ prior distribution is assumed for $p$.
}

of a positive association. The association between the signs of forecast revisions and $C A R$ is generally weaker in comparison to $R E T .^{22}$ Results for

${ }^{22}$ As a way of including zero revision observations return portfolios using a positive $\left(F_{p}\right)$, zero $\left(F_{2}\right)$, or negative $\left(F_{n}\right)$ revision classification were formed. An $n$-sample version of the Mann-Whitney test based on ranks [see discussion of the Jonckheere-Terpstra test in Hollander and Wolf (1973)] was performed on the null hypothesis $F_{n} \geq F_{z} \geq F_{p}$ against the ordered alternative $F_{n}<F_{z}<F_{p}$. The null was rejected in each year and all years combined at signifcance levels below 0.001 for both raw and abnormal returns. 
the $C A R$ variable in 1983 indicate an insignificant association. The lower significance levels for 1983 may be due, in part, to the relatively large number of observations lost to stock splits in that year. The results for the combined years are not sensitive to the choice of cumulation interval. Individual year results are, in general, unchanged as well..$^{23}$

The evidence indicates a statistically significant positive association between the sign of cumulative returns between forecasts and the sign of subsequent revisions for Value Line data. While there are no equivalent tests in the empirical literature based solely on the signs of these variables, the results are consistent with parametric tests reported for other analyst forecast sources covering different sample periods. ${ }^{24}$

\subsection{Tests of association between prior returns and forecast errors}

The tests of this section attempt to distinguish whether analysts' forecasts fully incorporate information in prior price changes. Proposition 2 indicates that if prior price changes are not reflected in analysts' forecasts, then the probability that a low earnings forecast is inaccurate (negative forecast error) increases when preceded by a positive price change and decreases when preceded by a negative price change. Similarly, the probability that a high earnings forecast is inaccurate (a positive forecast error) increases when preceded by a negative price change and decreases when preceded by a positive price change.

The following statistic is calculated to test the proposition:

$$
\text { freq }[\text { Error }<0 \mid \text { Returns }>0]-\text { freq }[\text { Error }<0 \mid \text { Returns }<0]>0 .^{25}
$$

\footnotetext{
${ }^{23}$ Define a change from above (below) to below (above) a 0.05 significance level for rejecting the null as a qualitative difference in the results. Then the only qualitative changes were as follows: A cumulation interval for abnormal returns between consecutive public forecast dates yields a significance level of 0.049 for 1983 as compared to the value of 0.34 reported in table 3 . A cumulation interval for raw returns that runs from ten days before the previous public forecast date to ten days before the public forecast date leads to an insignificant association in 1983 (the significance level changes from 0.031 reported in table 3 to 0.24 ) and a weaker association for 1984 (the significance level changes from 0.002 reported in table 3 to 0.08 ).

${ }^{24} t$-tests for significant differences between the mean returns of portfolios based on the sign of revisions and the overall mean return result in similar conclusions to those reported for the nonparametric tests above. These tests are based on the aggregate sample standard deviation. One-way layouts based on a pooled standard deviation weighted by the number of observations in each revision portfolio also indicate a descending order of the magnitude of mean returns to the positive, zero, and negative revision portfolios, respectively. Scheffe multiple comparisons of all pairs of individual portfolio means lead to rejection of identical means at standard confidence levels.

${ }^{25}$ In a two earnings state world this is simultaneously a test of: freq[ Error $>0 \mid$ Returns $\left.<0\right]-$ freq $[$ Error $>0 \mid$ Returns $>0]>0$.
} 
Table 4

Approximate randomization tests.

Forecast error $\equiv$ (Revised earnings forecast - Actual earnings)

Statistic: freq[ Error $>0 \mid$ Returns $<0]-$ freq[ Error $>0 \mid$ Returns $>0]$

\begin{tabular}{rllll}
\hline 1981 & 1982 & 1983 & 1984 & $\begin{array}{c}\text { All } \\
\text { years }\end{array}$ \\
\hline
\end{tabular}

The association between the sign of forecast errors and the sign of prior cumulative returns ${ }^{a}$ Raw returns

\begin{tabular}{|c|c|c|c|c|c|c|c|c|c|c|c|c|c|c|c|}
\hline & & & & & & & & & & & & & & & \\
\hline & & + & & & + & - & & + & - & & + & - & & + & - \\
\hline Error & $\begin{array}{l}+ \\
-\end{array}$ & $\begin{array}{l}80 \\
98\end{array}$ & $\begin{array}{l}97 \\
54\end{array}$ & $\begin{array}{l}+ \\
-\end{array}$ & $\begin{array}{l}115 \\
100\end{array}$ & $\begin{array}{l}97 \\
52\end{array}$ & + & $\begin{array}{l}107 \\
99\end{array}$ & $\begin{array}{l}53 \\
35\end{array}$ & $\begin{array}{l}+ \\
-\end{array}$ & $\begin{array}{l}84 \\
93\end{array}$ & $\begin{array}{l}94 \\
59\end{array}$ & $\begin{array}{l}+ \\
-\end{array}$ & $\begin{array}{l}386 \\
390\end{array}$ & $\begin{array}{l}341 \\
200\end{array}$ \\
\hline $\begin{array}{l}\text { Statistic } \\
p \text { value }^{\mathrm{b}}\end{array}$ & & & & & $\begin{array}{l}0.1 \\
0.0\end{array}$ & & & & & & & & & & $\begin{array}{l}133 \\
001\end{array}$ \\
\hline $\begin{array}{l}\operatorname{prob}(p<0.01)^{c} \\
\operatorname{prob}(p<0.05) \\
\operatorname{prob}(p<0.10)\end{array}$ & & $\begin{array}{l}1 . \\
1 . \\
1 .\end{array}$ & & & $\begin{array}{l}0.0 \\
1.0 \\
1.0\end{array}$ & & & $\begin{array}{l}0 . \\
0 . \\
0 .\end{array}$ & & & $\begin{array}{l}0 . \\
1 . \\
1 .\end{array}$ & & & $\begin{array}{l}1 . \\
1 . \\
1 .\end{array}$ & $\begin{array}{c}00 \\
00\end{array}$ \\
\hline
\end{tabular}

The association between the sign of revisions and the sign of prior cumulative abnormal returns ${ }^{a}$ $C A R$

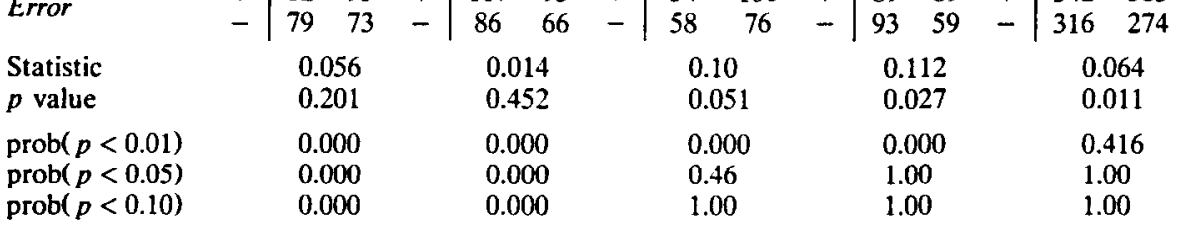

\footnotetext{
${ }^{a}$ Returns are cumulated between the previous public forecast date up to ten days before the public forecast date.

${ }^{b}$ Tests are based on one thousand shuffles of revisions relative to returns.

c Represents the posterior probability that the approximated significance level of the test is less than or equal to a given rejection level for the test. The significance level is a function of the number of shuffles and the number of times the test statistic for the shuffled data equals or exceeds the value computed for the original data. A uniform $[0,1]$ prior distribution is assumed for $p$.
}

Table 4 presents results and contingency tables categorized by the sign of the forecast error and the sign of prior raw returns ( $R E T)$ and prior abnormal returns $(C A R)$. Results for individual fiscal years and all years aggregated are reported. If the ex ante probabilities of negative and positive price changes are equal and the same is true for the probabilities of positive and negative forecast errors, then, under a null hypothesis of independence between the sign of forecast errors and prior returns, the proposed statistic in (4) is 
equivalent to the phi coefficient related to each contingency table. While the $C A R$ variable approximates this assumption about price changes the $R E T$ variable does not. Moreover, the evidence presented in section 3 indicates the possibility of a systematic upward bias in analysts' forecasts. For these reasons an approximate randomization test is used to assess the significance of the test statistic. ${ }^{26}$

The results reported in table 4 based on raw returns indicate that the null hypothesis of independence can be rejected below the 0.001 level for all years combined. ${ }^{27}$ Independence can be rejected at standard significance levels in every year except 1983 (0.101). The results based on abnormal returns, CAR, as a measure of price changes are similar for all years combined though relatively weaker. Independence between forecast errors and prior abnormal returns cannot be rejected for 1981 and 1982 at traditional significance levels. The results for all years combined are not sensitive to the choice of cumulation interval. Individual year results are, in general, unchanged under alternative cumulation periods. ${ }^{28}$

The evidence presented in this section fails to support the hypothesis that analysts' forecasts fully reflect the information in price movements occurring prior to their forecasts. In addition, the evidence is inconsistent with analysts 'simply re-expressing' price changes in their revisions. ${ }^{29}$

\section{Summary and conclusions}

The analysis in this paper suggests a positive association between earnings forecasts and prior price changes whether or not price changes are combined with analysts' private signals to formulate their forecasts. Further, if informa-

\footnotetext{
${ }^{26}$ As before the value of the proposed test statistic is similar to the phi coefficient calculated for each contingency table.

${ }^{27}$ Zero forecast error observations represent a small fraction of the total number. The differences in the values of the statistics calculated are not noteworthy. Therefore, the practice of excluding the zero forecast error observations from the contingency tables is adopted in these tests.

${ }^{28}$ Define a change from above (below) to below (above) a 0.05 significance level for rejecting the null as a qualitative difference in the results. Then the only qualitative changes were as follows: Cumulating abnormal returns between consecutive public forecast dates leads to rejection of the null hypothesis at a lower significance level than that reported in table 4 for 1983 (0.021 compared to 0.051 ) and a higher level for 1984 (0.101 compared to 0.027). Similarly, cumulating abnormal returns from ten days before the previous public forecast date to ten days before the public forecast date results in rejecting the null hypothesis at a lower significance level than that reported in table 4 for 1983 (0.017 compared to 0.051 ) and a higher level for 1984 (0.09 compared to 0.027).

${ }^{29}$ Equivalently, the evidence is inconsistent with the hypothesis that price changes actually mirror the private information that analysts have acquired and a delay in their public dissemination makes it appear as if forecasts trail price changes.
} 
tion in price changes is omitted from analysts' forecasts these price changes will predict the sign of the forecast errors.

The empirical evidence fails to support the hypothesis that analysts' forecasts fully incorporate prior price changes. The results are consistent with analysts omitting price change information from their earnings forecasts.

One explanation for the result is that analysts are inefficient in collecting and interpreting publicly observable signals. One problem with this explanation is that it requires that analysts fail to recognize their tendency to underweight information over the reasonably long period covered by the sample.

A second explanation for the results is that the private information is more easily inferred by investors if it is not combined with other signals whose information content is open to individual interpretation. ${ }^{30}$ This explanation is consistent with the casual observation that analysts often leave forecasts outstanding for long periods even after fairly large price changes are observed. This behavior may be indicative of analysts having incentives to provide a new forecast only when they have obtained new private information independently of price changes.

An important implication of this study concerns how analysts' forecasts, which have generally been conceded to be more accurate than time series models, should be incorporated as a measure of market expectations. The results suggest that two identical forecasts can be interpreted differently by market participants depending on price changes prior to the forecasts. It can be inferred, for example, that the distribution of forecasts (and, therefore, forecast errors) is potentially skewed in one direction when price changes of a particular sign prior to forecasts are prevalent. Moreover, if investors are aware of this fact they are likely to take it into account when forming their posteriors.

\section{References}

Abarbanell, J.S., 1989, Financial analyst information acquisition in response to security price changes, Doctoral dissertation (University of Pennsylvania, Philadelphia, PA).

Beaver, W.H., 1987, The properties of sequential regressions with multiple explanatory variables, The Accounting Review 1, 137-143.

Brown, P., G. Foster, and E. Noreen, 1985, Security analyst multi-year earnings forecasts and the capital market, Studies in Accounting Research, no. 21.

Brown, L.D., P. Griffin, R. Hagerman, and M. Zmijewski, 1987, Security analyst superiority relative to univariate time-series models in forecasting quarterly earnings, Journal of Accounting and Economics 9, 61-87.

\footnotetext{
${ }^{30} \mathrm{~A}$ related argument is that it may be difficult to discern when the analyst's private information is subsumed by, subsumes, or is orthogonal to price changes because price changes commonly occur around the time forecast revisions are issued. If analysts report only their private information, this ambiguity in the timing and content of forecasts poses no interpretation problems for investors.
} 
Conover, W.J., 1971, Practical nonparametric statistics (Wiley, New York, NY).

Copeland, T.E. and D. Mayers, 1982, The Value Line enigma: A case study of performance evaluation issues, Journal of Financial Economics 3, 82-106.

Diamond, D.W. and R.E. Verrecchia, 1981, Information aggregation in a noisy rational expectations economy, Journal of Financial Economics 9, 221-235.

Elton, E.J., M. Gruber, and M. Gultekin, 1981, Expectations and share prices. Management Science 27, 975-987.

Fleiss, J.L., 1972, Statistical methods for rates and proportions (Wiley, New York. NY).

Fried, D. and D. Givoly, 1982, Financial analysts' forecasts of earnings: A better surrogate for market expectations. Journal of Accounting and Economics 4, 85-107.

Givoly, D. and J. Lakonishok, 1979, The information content of financial analysts' forecasts of earnings, Journal of Accounting and Economics 1, 165-185.

Givoly, D. and J. Lakonishok, 1984, Properties of analysts forecasts of earnings: A review and analysis of the research, Journal of Accounting Litcrature 3, 119-152.

Glosten, L. and P. Milgrom, 1985, Bid, ask and transaction prices in a specialist market with heterogeneously informed traders, Journal of Financial Economics 14, 71-100.

Hollander, M. and D. Wolfe, 1973, Nonparametric statistical methods (Wiley, New York, NY).

Holthausen, $\mathrm{K}$. and $\mathrm{R}$. Verrecchia, 1988, The effect of sequential information releases on the variance of price changes in an intertemporal multi-asset market, Journal of Accounting Research 1, 82-106.

Jain, P.C., 1988, Equity issues and changes in expectations of earnings by financial analysts. Working paper (University of Pennsylvania, Philadelphia, PA).

Noreen, E.W., 1989, Computer intensive methods for testing hypotheses: An introduction (Wiley, New York, NY).

O'Brien, P.C., 1988, Analysts' forecasts as earnings expectations, Journal of Accounting and Economics 10, 53-83.

Philbrick, D.R. and W.E. Ricks, 1990, Using Value Line and I/B/E/S analyst forecasts in accounting research, Working paper (Portland State University, Portland, OR).

Stickel, S.E., forthcoming, Predicting individual analyst earnings forecasts, Journal of Accounting Research.

Trueman, B., 1988, Do security analysts use their information fully in preparing their earnings forecasts?, Working paper (University of California. Los Angeles, CA). 